\title{
High Heat Flux Components - Readiness to Proceed from Near Term Fusion Systems to Power Plants
}

\author{
A. R. Raffray ${ }^{1}$, R. Nygren ${ }^{2}$, D. G. Whyte ${ }^{3}$
}

and the contributors to the International HHFC Workshop on Readiness to Proceed from

Near Term Fusion Systems to Power Plants:

S. Abdel-Khalik ${ }^{4}$, R. Doerner ${ }^{1}$, F. Escourbiac ${ }^{5}$, T. Evans ${ }^{6}$, R. J. Goldston ${ }^{7}$, D. T. Hoelzer ${ }^{8}$, S. Konishi $^{9}$, P. Lorenzetto ${ }^{10}$, M. Merola ${ }^{11}$, R. Neu ${ }^{12}$, P. Norajitra ${ }^{13}$, R. A. Pitts ${ }^{11}$, M. Rieth ${ }^{14}$, M. Roedig $^{15}$, T. Rognlien ${ }^{16}$, S. Suzuki ${ }^{17}$, M. S. Tillack ${ }^{1}$, C. Wong ${ }^{6}$

${ }^{1}$ CER, EBU-II, Room 460, University of California, San Diego, 9500 Gilman Drive, La Jolla, CA 92093-0417, USA

${ }^{2}$ Sandia National Laboratories, P.O. Box 5800, MS-1129, Albuquerque, NM 87185, USA

${ }^{3}$ Plasma Science and Fusion Center, MIT, 77 Massachusetts Ave., NW17-105

Cambridge, MA 02139-4307, USA

${ }^{4}$ Mechanical Engineering 0405, Georgia Institute of Technology, Atlanta, GA 30332, USA

${ }^{5}$ CEA, IRFM, F-13108 St Paul Lez Durance, France

${ }^{6}$ General Atomics, P.O. Box 85608, 3550, San Diego, CA 92186, USA

${ }^{7}$ Princeton Plasma Physics Laboratory, MS-41, Princeton, NJ 08543, USA

${ }^{8}$ Oak Ridge National Laboratory, P.O. Box 2008, MS-6136, Oak Ridge, TN 37831, USA

${ }^{9}$ Institute of Advanced Energy, Kyoto University, Gokasho, Uji, Kyoto 611-0011, Japan

${ }^{10}$ Fusion For Energy, C/ Josep Pla 2, Torres Diagonal Litoral B3, 08019 Barcelona, Spain

${ }^{11}$ ITER Organization, Cadarache Centre, Bat 524, F-13108 Saint Paul lez Durance, France

${ }^{12}$ Max-Planck Institut für Plasmaphysik, Euratom Association, 85748 Garching, Germany

${ }^{13}$ Forschungszentrum Karlsruhe, Institute for Materials Research III, P.O. Box 3640, D76021 Karlsruhe, Germany

${ }^{14}$ Forschungszentrum Karlsruhe, Institute for Materials Research I, P.O. Box 3640, D76021, Karlsruhe, Germany 


\author{
${ }^{15}$ Forschungszentrum Jülich, D-52425 Jülich, Germany \\ ${ }^{16}$ Lawrence Livermore National Laboratory, Livermore, CA, USA \\ ${ }^{17}$ Fusion Research and Development Directorate, Japan Atomic Energy Agency, Naka-shi, \\ Ibaraki-ken, 311-0193 Japan
}

May 20, 2009

\begin{abstract}
A present topic of high interest in magnetic fusion is the "gap" between near-term and longterm concepts for high heat flux components (HHFC), and in particular their application in divertors. This paper focuses on this issue with the aim of characterizing the international status of current HHFC design concepts for ITER and describing the different technologies needed in the designs being developed for fusion power plants. Critical corresponding material and physics aspects are highlighted while evaluating the current readiness level of long-term concepts, identifying the design and R\&D gaps, and discussing ways to bridge them.
\end{abstract}




\section{Introduction}

The differences in technology between near-term and long-term concepts for high heat flux components (HHFC, and in particular divertors) and the related issues to be resolved and technical gaps that require research and development is a topic of high current interest and the subject of this paper. The specific objectives presented here are (1) an improved characterization of current HHFC design concepts for power plants, including the status of various programs worldwide; (2) a comparison of this characterization to the present stage of development and experimental information for near term concepts, e.g., the International Thermonuclear Experimental Reactor (ITER); and (3) an exploration of how to evaluate the current status with respect to the end goal (power plant HHFC concepts) and what needs to be done to close the gap between existing abilities and future needs.

Implicit in these objectives is some definition of a DEMO (demonstration power plant). One aspect is that this definition should have a physics regime for operating a power plant that has realistic and at least generally self-consistent parameters coupled with supportable choices for the technology for HHFCs. Two important considerations in this regard require that:

(1) the corresponding heat and particle fluxes on the divertor and first wall (FW) are consistent with the current state of knowledge, for example, what has been learned in the last few years in the ITER Project about the distribution of heat and particle loads for steady state operation and transient events; and

(2) the choices of materials are consistent with the current state of knowledge and recognitions of issues with regard to their ranges of service temperatures and responses to threats from the fusion environment, such as degradation of mechanical or thermal properties due to damage from energetic particles (including neutrons) and related effects on tritium retention and production of dust.

There is not currently a worldwide consensus on the definition of a DEMO. Some definitions consider DEMO as the next logical step beyond ITER (e.g. in the E.U. [1]) , which may comprise a testing phase followed by a demonstration phase. In the U.S., DEMO is generally considered as a demonstration power plant employing the same physics and technology as the first generation of competitive commercial power plants to follow [2]. This presumes development and qualifications of HHFCs and tritium breeding blankets in preDEMO confinement devices. In addition, some options are based on alternative (non- 
tokamak) confinement concepts and/or with technology such as liquid surfaces exposed to the plasma. Clearly there is a broad range of what we call "technology gaps" if all possibilities are to be considered, and this paper does not span that broad scope.

This paper results in major part from very informative presentations and discussions at the "International HHFC Workshop on Readiness to Proceed from Near Term Fusion Systems to Power Plants," which was held at the University of California, San Diego (UCSD) on December 10-12, 2008 [3]. To force the agenda and discussions into a manageable forum, the workshop focused mainly on HHFCs with solid surfaces applied to tokamaks. Many findings would also be applicable for other magnetic configurations, such as stellarators, and some presentations on alternative confinement concepts and liquid walls were also included in the workshop. An important aspect of this workshop was the participation by experts from the US and abroad that spanned many disciplines. Also the limited number of participants and the time for discussion permitted the workshop leaders and participants to explore a variety of important issues and in some cases reach conclusions.

In addition to the above considerations, this workshop was conducted also with the awareness that the US fusion program was organizing a large effort in strategic planning called the Research Needs Workshop or ReNeW. This extensive 8-month planning activity is drawing upon experts in the US fusion community to examine the current research in the US fusion program and identify research gaps and needs for the next 10-20 years. The five themes in this activity included "Taming the Plasma Interface" (primarily on HHFCs) and "Harnessing Fusion Power" (which dealt with fusion nuclear technology). Readers interested in this paper may also wish to learn more about ReNeW and the future output from its discussions.

The paper is organized in the following sections. Sections 2 and 3 are summaries respectively of near-term HHFC design and R\&D (mainly ITER) and long-term HHFC concepts and R\&D (DEMO and power plants). Section 4 summarizes information on issues related to structural materials (4.1) and plasma materials interactions (4.2) that affect the choice of materials and the integration of these choices into the expected performance of the HHFCs. Section 5 summarizes the key physics considerations for near term and long term concepts and the relation to the requirements for HHFCs. Section 6 presents an approach called a Technical Readiness Level (TRL) that is offered here as a possible tool in evaluating current readiness levels vis-à-vis the long term objective. Section 7 discusses the key gaps between near-term 
and long-term concepts in light of the information provided in the preceding sections and includes ideas on how to fill these gaps.

\section{Near Term HHFC Design and R\&D}

This section focuses on ITER, which is now at the center of much of the world's research efforts in fusion. The challenging requirements for its HHFCs represent both a large step beyond the requirements of previous fusion devices but also an extension of a large development effort that has been ongoing for over two decades.

\subsection{ITER Plasma Facing Materials}

An important challenge in designing the ITER PFCs is the need to accommodate not only steady state (or quasi steady-state) heat loads but a number of different off-normal scenarios, which are of concern due to transient heat loading on HHFCs, including [4]:

- $\quad$ Major disruptions:

- Peak energy density parallel to the field in the divertor at the separatrix: 100 - 600 $\mathrm{MJ} / \mathrm{m}^{2}$ (outer plate); 130 - $780 \mathrm{MJ} / \mathrm{m}^{2}$ (inner plate).

- Projecting these values onto the target plates gives:

- Outer plate: $\sim 4$ - $25 \mathrm{MJ} / \mathrm{m}^{2}$

- Inner plate: $\sim 7-40 \mathrm{MJ} / \mathrm{m}^{2}$

- $\quad$ Deposition time 1.5-3 ms (rise time), 1.5-6 ms (decay time)

- $\quad$ Vertical Displacement Events (VDEs) - power deposition on upper wall blanket shield modules (upward VDE), divertor dome, baffle or lower blanket shield modules (downward VDE):

- $\quad$ Power flux outside divertor (mapped to outer mid-plane) parallel to field lines near the separatrix at wall/baffle/dome contact $=800 \mathrm{MW} / \mathrm{m}^{2}$

- $\quad$ Energy deposition on outer wall blanket shield modules (accounting for component shaping) 20-30 MJ/m² (upward and downward VDEs).

- $\quad$ Timescales $~ 0.1$ / $0.3 \mathrm{~ms}$ (downward / upward).

- ELMs: 
- Maximum energy density on divertor target for:

- Controlled ELMs: $0.5 \mathrm{MJ} / \mathrm{m}^{2}$ (inner plate); $0.3 \mathrm{MJ} / \mathrm{m}^{2}$ (outer plate)

- Uncontrolled ELMs: $10 \mathrm{MJ} / \mathrm{m}^{2}$ (inner plate); $6 \mathrm{MJ} / \mathrm{m}^{2}$ (outer plate)

- $\quad$ Deposition time $~ 0.25-0.5 \mathrm{~ms}$

- $\quad$ Frequency (controlled/uncontrolled) $=20-40 / 1-2 \mathrm{~Hz}$

The current ITER plans include three different plasma-facing materials (PFM) for the initial operation phase, as illustrated in Figure 1: beryllium for the first wall (based on its acceptable effect on plasma performance and its high oxygen gettering characteristic); tungsten for the dome and baffle divertor regions (based in its temperature capability and low physical sputtering yield by neutral particles); and carbon-fiber-composite (CFC) for the divertor vertical targets. CFC has high thermal shock resistance, does not melt and has been widely used as a PFM in plasma experimental devices, showing good compatibility over a wide range of plasma parameters. However, a key issue with carbon is tritium codeposition and the difficulty of removing tritium in particular in colder shadowed areas. The current ITER divertor armor strategy reflects this key concern [5]:

1) The first divertor set will have both carbon and tungsten armor on the vertical targets, with carbon in the highest heat load region. This is based on the proven range of compatibility of carbon with a number of plasma conditions in present devices, particularly at low densities with significant additional heating. CFC also promises to make the development of techniques for ELM control and disruption mitigation easier (as compared to $\mathrm{W}$ ) by taking advantage of the larger tolerance of the plasma to $\mathrm{C}$ and of the absence of melting which may present a problem of irreparable damage to the strike point surfaces, requiring the replacement of divertor modules.

2) The second divertor set will have full-tungsten armor on the vertical targets and is envisaged for later installation after the initial operational phase, and almost certainly before the tritium phase to avoid the tritium co-deposition issue with carbon. However, so as not to completely preclude the possible use of carbon early in the D-T phase, the first divertor set is designed to accommodate the heat loads foreseen in the D-T phase.

\section{INSERT FIGURE 1}




\subsection{ITER Divertor Design}

The main functions of the ITER divertor system are to exhaust the major part of the plasma thermal power (including alpha power) and to minimize the helium and impurity content in the plasma. The design consists of 54 cassettes in a circular array held in position by two concentric radial rails [5]. The divertor cassette body is reusable to minimise activated waste; it provides neutron shielding, routes the water coolant and supports the different plasma facing components (PFCs). These consist of the dome, particle reflector plates, and inner and outer vertical targets, as illustrated in Fig. 2. The inner and outer vertical targets (VTs), are the PFCs that, in their lower part, intercept the magnetic field lines, and therefore remove the heat load coming from the plasma via conduction, convection and radiation. As shown in Fig. 3, the lower part of the VT consists of a number of CFC monoblocks while the upper part is made up of $\mathrm{W}$ monoblocks. The CFC or $\mathrm{W}$ monoblock is bonded to the CuCrZr coolant tube via a $\mathrm{Cu}$ interlayer. A swirled tape is used in the coolant tube to increase the critical heat flux. The armor thickness is based on maximizing the lifetime of the divertor while keeping the maximum armor material temperature at an acceptable level. The design requirements for the PFCs include [5]:

- 3000 equivalent pulses of $400 \mathrm{~s}$ duration at nominal parameters, including 300 slow transients.

- During normal operational conditions, the design surface heat flux on the vertical target is up to $10 \mathrm{MW} / \mathrm{m}^{2}$ in the strike point region and $5 \mathrm{MW} / \mathrm{m}^{2}$ in the baffle region.

- Under slow transient thermal loading conditions, the design surface heat flux on the lower divertor vertical target geometry is up to $20 \mathrm{MW} / \mathrm{m}^{2}$ for sub-pulses of less than $10 \mathrm{~s}$.

- The dome shall sustain heat fluxes of up to $5 \mathrm{MW} / \mathrm{m}^{2}$.

- The umbrella and the particle reflector plates shall sustain local heat flux up to 10 $\mathrm{MW} / \mathrm{m}^{2}$, which can be transiently swept across the surface (about $2 \mathrm{~s}$ ) as the plasma is returned to its correct position.

- $\quad$ The maximum $\mathrm{N}$-volumetric heating in the vertical target $=10 \mathrm{MW} / \mathrm{m}^{3}$.

- Off-normal loading conditions under events such as disruptions and ELMs as specified by the physics analysis (see Section 2.1 ). 
INSERT FIGURES 2 AND 3

Detailed design analyses have been performed for the divertor, which is now on the eve of procurement. These include thermal analyses under time averaged and transient loads (plasma fluxes and radiation specified by physics), electromagnetic finite element modeling (VDE forces) and hydraulic analysis of whole cassette (cooling water pressure drops, draining and dry). The design parameters for the divertor subcooled water coolant include:

- $\quad$ Inlet temperature $=100{ }^{\circ} \mathrm{C}$

- $\quad$ Inlet water pressure $=4.2 \mathrm{MPa}$

- $\quad$ Total pressure drop $<1.4 \mathrm{MPa}$

- Total flow rate $<1000 \mathrm{~kg} / \mathrm{s}$

- $\quad$ Critical heat flux margin $>1.4$

\subsection{Supporting R\&D and Qualification Testing for ITER Divertor}

A long and extensive R\&D and qualification campaign has been planned and performed in support of the ITER divertor in order to arrive at this stage of readiness (edge of procurement). The strategy for component engineering and material choice considered industrially available materials while taking into account their physical and mechanical properties, maintainability, reliability, corrosion performance and safety requirements at the ITER operational conditions. Experience from current tokamaks was taken into account for functional materials (plasma facing, diagnostics materials, etc.) and knowledge from fission neutron irradiation programs was also utilized. This resulted in three in-vessel materials categories:

- Standard materials with established manufacturing technologies, directly applicable to ITER (e.g. steels 316L(N), Ni-based alloy type 625, W).

- Standard materials, which require some modifications, such as more stringent limits on the alloying elements and appropriate fabrication routes (e.g. CuCrZr alloys).

- Materials requiring new developments (e.g. CFC) or new joining techniques (e.g. Be, CFC, W with CuCrZr alloy by Hot Isostatic Pressing, Hot Radial Pressing, brazing). 
The development and validation campaign comprised fabrication and testing of progressively larger and more integrated mockups, up to a full-scale divertor target, as illustrated in Fig. 4 [6]. Experiments included thermal-hydraulic, critical heat flux (CHF) and high heat flux testing of different mock-ups. In addition to the quasi-steady state loads, the divertor PFCs will also be subject to high transient loadings in the case of off-normal events as mentioned above. These might lead to loss of armor through melting (for $\mathrm{W}$ ) and evaporation (W and CFC) as well as impacting the joints.

\section{INSERT FIGURE 4}

During the last few years, great progress has been made in the development of joining techniques for high heat flux components [7]. In the frame of the qualifying process testing of these components under operational relevant loading conditions is indispensable. Electron beam facilities are very flexible machines for the simulation of operational conditions. The electron beam facilities JUDITH-1 and JUDITH-2 (in Forschungszentrum Jülich (FZJ)) are used for the simulation of ITER-relevant loading conditions on unirradiated and on neutron irradiated PFMs and PFCs [8], whereas the complementary European AREVA-CEA electron beam 200 kW FE200 facility provides the capability for testing larger unirradiated mock-ups [9]. Due to the lack of an intense $14 \mathrm{MeV}$ neutron source, complex neutron irradiation experiments have been performed in material test reactors to quantify the neutron induced material damage. These tests provide the required data base on the degradation of thermal and mechanical parameters. In addition, the thermal fatigue and thermal shock performance of irradiated high heat flux components is another important issue for the engineering design, the licensing and the safe operation of future fusion reactors.

Experiments in the FE200 and JUDITH facilities confirmed that technical solutions for cyclic thermal loads up to about $20 \mathrm{MW} / \mathrm{m}^{2}$ are available. Especially CFC- and Wmonoblocks (illustrated in Fig. 5) represent a very robust design solution, overall showing successful accommodation of up to $23 \mathrm{MW} / \mathrm{m}^{2}$ x 2000 cycles for CFC and $15 \mathrm{MW} / \mathrm{m}^{2} \mathrm{x}$ 2000 cycles for $\mathrm{W}$, and $10 \mathrm{MW} / \mathrm{m}^{2}$ x 3000 cycles for both CFC and $\mathrm{W}$ [6].

\section{INSERT FIGURE 5}


The effect of irradiation was also investigated up to the expected dpa level in ITER $(\sim 0.5$ dpa at end of lifetime; 3000 shots at different power densities). W-monoblocks do not show any degradation after neutron irradiation, being successfully tested to $18 \mathrm{MW} / \mathrm{m}^{2} \mathrm{x} 1000$ cycles following irradiation at $200^{\circ} \mathrm{C}$ to $0.5 \mathrm{dpa}$ [6]. The CFC monoblock was successfully tested to $15 \mathrm{MW} / \mathrm{m}^{2}$ x 1000 cycles following irradiation at $200^{\circ} \mathrm{C}$ to $1 \mathrm{dpa}$. However, due to the bad thermal conductivity after neutron irradiation, CFC-monoblocks showed increased surface temperatures leading, beyond $14 \mathrm{MW} / \mathrm{m}^{2}$, to an enhanced erosion due to sublimation of carbon $[6,8]$.

During transient loads, tungsten and CFC both show damage for energy densities higher than about $0.5 \mathrm{MJ} / \mathrm{m}^{2}$, as illustrated in Fig. 6. Tungsten starts melting (first on the tile edges and at higher energy densities on the whole surface) and deformed tungsten shows cracking after repetitive ELM-like loading [10]. After neutron irradiation both materials show degradation [10]. For tungsten loaded below the melting threshold, enhanced cracking is observed, while CFC shows an increased erosion, mainly due to the reduced thermal conductivity.

\section{INSERT FIGURE 6}

The CHF test campaign was also very successful in helping to come up with a design with an acceptable operating margin. The use of pressurized water as coolant in ITER provides the capability to handle heat fluxes in the range $10-20 \mathrm{MW} / \mathrm{m}^{2}$. This target can be attained with well-adapted thermal-hydraulics parameters for sub-nucleate boiling regime and turbulence promoters to reach heat transfer coefficients in the range of $50,000-100,000 \mathrm{~W} / \mathrm{m}^{2} / \mathrm{K}$. However, the resulting CHF margin is a key issue. To understand and mitigate this risk, a program of ITER-focused investigations was performed over the last 15 years [e.g. 11]. In addition to modelling work, testing protocols were defined and culminated in the building of a solid experimental database (e.g. more than 200 points from testing done at CEA).

Different concepts including smooth tubes, swirl tube, hypervapotrons, annular flows were tested. The impact of design parameters such as the width of the tubes (e.g. toroidal extension), internal tube diameter, thickness and twist ratio of the tapes was assessed. A range of thermal-hydraulics parameters was also investigated, including water pressure, 
velocity, temperature and effect of peaked poloidal heat flux. As a general rule, CHF increases with twist ratio, tape thickness, water pressure or water velocity but decreases with increasing width of the tube or water temperature. An adaptation of the TONG75 correlation was proposed by CEA as a predictive tool, taking the above effects into account through hydraulic diameter and empirical coefficients. The CHF tests have also helped develop a whole set of correlations for heat transfer prediction both in convective and sub-nucleate boiling regime, as illustrated in Figure 7.

These predictive tools have been used for the Tore Supra and W7-X PFC designs as well as for ITER. With regard to the divertor, the lowest CHF margin was found to be 1.4 for the CFC monoblock under a $20 \mathrm{MW} / \mathrm{m}^{2}, 10 \mathrm{~s}$ pulse at the end of life (7-mm CFC thickness). The allowance for acceptable potential bonding defect at the $\mathrm{CFC} /$ heat sink interface (raising the local surface temperature by $\sim 50-60^{\circ}$ ) was also considered. Table 1 summarizes the results.

\section{INSERT FIGURE 7}

\section{INSERT TABLE 1}

\section{Long Term HHFC Design and R\&D (DEMO and Power Plant)}

\subsection{Power Plant Plasma Facing Materials}

Little work has been done on the PFM choice for the first wall of a DEMO or power plant, and of its interaction with and impact on plasma performance. For example, in the power plant designs performed as part of the ARIES program, both the possibility of using a bare wall (i.e. with no dedicated PFC armor) or a thin W armor layer had been considered. In the case of a Dual Coolant Lithum Lead (DCLL) blanket [12], the bare wall would be a ferritic steel wall. In any case, for both bare wall or thin $\mathrm{W}$ armor cases, the plasma facing material temperature will be fairly high, about $600-800^{\circ} \mathrm{C}$.

The ITER PFCs are designed for a number of different off-normal scenarios, including disruptions, VDEs and ELMs. This includes accommodation of electro-magnetic forces as 
well as of energy deposition. In the latter case, the use of low temperature water and optimized armor thickness help provide for acceptable PFC lifetime. In contrast, power plant or DEMO PFCs are cooled by higher temperature He with little margin for accommodating off-normal thermal loads. A simple parametric study of off-normal energy deposition on a DEMO or power plant first wall was performed to assess the impact on the PFC lifetime. It is recognized that in addition to accommodation of the thermal loads, the FW and blanket would have to be designed to also withstand the EM loads.

Transient events such as VDE's and ELM's would result in substantial energy deposition on the PFCs. The exact energy deposition values would depend on the power plant PFC configuration and plasma characteristics. For example, the fusion power in a power plant will be at least 4-5 times higher than for ITER with a corresponding increase in the transient energy deposition values. For simplicity, an assessment was carried out based on ITER-like range of values (as lower-bound for a power plant), assuming an incident energy deposition on the PFC of the order of $1-10 \mathrm{MJ} / \mathrm{m}^{2}$ over $\sim 1-3 \mathrm{~ms}$ for disruption and also of the order of 1$10 \mathrm{MJ} / \mathrm{m}^{2}$ for ELMs (with a frequency of 1-4 Hz). For VDEs an incident energy density of 30-60 MJ/m² over 0.1-0.3 s was assumed. The RACLETTE code [13] was used for modeling the impact of the energy deposition on the first wall. The analysis was carried out for the first wall of a dual-coolant-lithium-lead (DCLL) blanket for 2 cases: a ferritic steel first wall coated with a 1-mm W armor; and a bare ferritic steel wall. Example results for transient energy depositions on the W-coated first wall are shown in Fig. 8. From the figure, about $0.1 \mathrm{~mm}$ of $\mathrm{W}$ is melted and $0.01 \mathrm{~mm}$ evaporated under an energy deposition of $\sim 4-5$ $\mathrm{MJ} / \mathrm{m}^{2}$. Similar results were obtained for the bare wall case. From the overall analysis, the following observations can be made:

- Only a few disruptions can be accommodated per year (depending on the energy density).

- VDEs cannot be accommodated.

- Only a limited number of uncontrolled ELM cases can be accommodated.

- Controlled ELMs might be acceptable (in particular for the W-armor case) depending on the energy deposition density.

- The impact of such disruption and ELM transient energy deposition scenarios would be even more severe for the high-temperature, W-armored divertor concepts currently considered for power plants (described in section 3.2).

- Avoidance or mitigation of transient events (disruptions, uncontrolled ELMs, VDEs) is a key requirement for power plant applications. 


\section{INSERT FIGURE 8}

\subsection{Power Plant Divertor Design and $R \& D$}

For DEMO and power plant divertors, the high operating temperature and irradiation levels preclude the use of $\mathrm{Cu}$ and the required thermal conductivity ( 100 W/m-K) and maximum allowable temperature $\left(>1000^{\circ} \mathrm{C}\right)$ rules out ferritic steel as structural material. The only possibility is then a refractory alloy, W-alloy being an attractive candidate if it can be developed to operate under irradiation with a reasonable temperature window. Thus, most recent DEMO or power plant divertor design studies in the US and the EU utilize a Hecooled W-alloy configuration to provide high temperature operation for high power cycle efficiency.

The proposed concepts range in scale from a plate configuration with characteristic dimension of the order of $1 \mathrm{~m}[14,15]$, to the ARIES T-tube configuration with characteristic dimension of the order of $10 \mathrm{~cm}[12,16]$, to the EU FZK finger concept with characteristic dimension of the order of $2 \mathrm{~cm}[17,18]$. The trend in moving to smaller-scale units is to minimize the thermal stress under a given heat load; however, this is done at the expense of increasing the number of units (for an example tokamak case, from $\sim 750$ to 110,000 to $\sim 535,000$ for the plate, T-tube and finger concepts, respectively) with a corresponding impact on the reliability of the system. All these designs utilize tungsten or tungsten alloy as structural material. It is a low-activation material and possesses a high melting point, high thermal conductivity, and low thermal expansion. Its disadvantages lie in the relatively small operation temperature window, which is dictated by the ductile-brittle transition temperature (DBTT) at the lower boundary and the recrystallization temperature (RCT) at the upper boundary. The RCT and machinability of tungsten can be improved by adding fine oxide particles. A serious material $R \& D$ effort is required: (a) to widen the $\mathrm{W}$ alloy operating temperature range from $\sim 600-700^{\circ} \mathrm{C}$ (governed by $\mathrm{W}$ ductility considerations) to enable coupling to an oxide-dispersion-strengthened (ODS) ferritic steel manifold, to $\sim 1300^{\circ} \mathrm{C}$ (governed by the $\mathrm{W}$ recrystallization limit) to provide desirable high-temperature capability; and (b) to develop an ODS ferritic steel offering acceptable strength properties up to about $750^{\circ} \mathrm{C}$ (e.g. nano-sized ODS FS). 
As example concepts, the finger design and the T-tube design are briefly described below together with a summary of their supporting R\&D. It must be noted also that all these concepts are designed to for the given maximum heat flux $\left(\sim 10 \mathrm{MW} / \mathrm{m}^{2}\right)$ with little margin to accommodate any upward uncertainty in this heat flux.

\subsubsection{EU Divertor Concept for Power Plant}

The current reference concept is the He-cooled modular divertor with jet cooling (HEMJ), illustrated in Fig. 9 [17,18]. It relies on impingement cooling with high-pressure helium (10 $\mathrm{MPa}$ ) with a resulting pressure drop at the jet of $\sim 0.12 \mathrm{MPa}$ for $\mathrm{He}$ inlet and outlet temperatures of $600^{\circ} \mathrm{C}$ and $700^{\circ} \mathrm{C}$, respectively. The concept comprises small tiles made of tungsten, which are brazed to a thimble made of tungsten alloy $\mathrm{W} 1 \% \mathrm{La}_{2} \mathrm{O}_{3}$ (WL10). The W finger units are connected to the main structure of ODS Eurofer steel by means of a transition piece based on copper casting or brazing with mechanical interlock.

\section{INSERT FIGURE 9}

Technological studies were performed on manufacturing of the $\mathrm{W}$ finger mock-ups. For testing purposes the divertor tile and thimble parts were mechanically manufactured from the full material. For the W/WL10 joint the brazing material STEMET® 1311 (brazing temperature $=1050^{\circ} \mathrm{C}$ ) was used. This joint is aimed at stopping the cracks induced by the heat load and growing from the top tile surface. The second brazed joint lies between WL10 and ODS Eurofer steel, with an operational temperature of about $700^{\circ} \mathrm{C}$. It has a function of compensating the mismatch of different thermal expansion coefficients of the two parts. Besides the copper cast joining method, the 71KHCP (Cobalt-based) brazing filler metal $\left(\mathrm{T}_{\text {braze }}=1050^{\circ} \mathrm{C}\right.$ ) was applied at this $\mathrm{W}$-steel transition joint of certain mock-ups. In both cases a sufficient ductility of the brazing fillers is required.

In cooperation with the Efremov Institute a combined helium loop and electron beam facility (200 kW, $40 \mathrm{keV}$, Fig. 2) was built in St. Petersburg, Russia, for experimental verification of the design, as illustrated in Fig. 10. It enables mock-up testing at a nominal helium inlet temperature of $600^{\circ} \mathrm{C}$, an internal pressure of $10 \mathrm{MPa}$, and a pressure drop in the mock-up of up to 0.5 MPa. Several high heat flux tests were successfully performed on mock-ups such as those shown in Fig. 11 [18]. 
INSERT FIGURE 10

\section{INSERT FIGURE 11}

The results of the first test series in 2006 already confirmed the performance of the divertor module under $10 \mathrm{MW} / \mathrm{m}^{2}$. For the second and third test series in 2007-2008, the mock-ups were further improved in view of thermal stress reduction as well as the manufacturing quality of the parts. This brought a noticeable improvement in performance and resistance against thermal cyclic loadings. The last successfully tested mock-ups survived outstandingly more than 100 cycles under $10 \mathrm{MW} / \mathrm{m}^{2}$ without any damages. Post-examination and characterization of the mock-ups subjected to the HHF tests are in progress at FZJ. Altogether, these initial test results confirm the high heat flux capability of this concept and serve as a strong stepping stone for further development of the material and concept and more integrated testing.

\subsubsection{US T-tube Divertor Concept for Power Plant}

The ARIES T-tube concept is a mid size unit, $\sim 15 \mathrm{~mm}$ in diameter and $100 \mathrm{~mm}$ long, capable of accommodating at least $10 \mathrm{MW} / \mathrm{m}^{2}[12,16]$. As illustrated in Fig. 12, it consists of a W-alloy inner cartridge and outer tube on top of which a W castellated armor layer is attached. Both W alloy pieces are connected to a base ODS FS unit through a graded transition to minimize thermal stresses. The helium coolant is routed through the inner cartridge first and then pushes through thin slots $(\sim 0.4 \mathrm{~mm})$ to cool the heat-loaded outer tube surface. The design provides some flexibility in accommodating the divertor area since a variable number of such T-tubes can be connected to a common manifold to form the desired divertor target. The required He flow rate is $\sim 6 \mathrm{~kg} / \mathrm{s}$ per $\mathrm{m}^{2}$ of divertor plate surface with a corresponding pressure drop of $\sim 0.11 \mathrm{MPa}$ through the jet region. For He inlet/outlet temperatures of $570^{\circ} \mathrm{C} / 700^{\circ} \mathrm{C}$ and a surface heat flux of $10 \mathrm{MW} / \mathrm{m}^{2}$, the maximum $\mathrm{W}$ alloy temperature is $1240^{\circ} \mathrm{C}$ (within the $1300^{\circ} \mathrm{C}$ assumed recrystallization limit) and the maximum combined primary and secondary stresses are 342 MPa, as illustrated in Fig. 13.

INSERT FIGURE 12 


\section{INSERT FIGURE 13}

As part of the initial R\&D effort on this concept, the high thermal-hydraulic performance of the jet flow (with an effective heat transfer coefficient of $\sim 40 \mathrm{~kW} / \mathrm{m}^{2}-\mathrm{K}$ ) was confirmed through a series of small scale experiments at the Georgia Institute of Technology [19]. The tests included mock-ups closely matching the geometry of the proposed divertor module designs (including the T-tube and also the finger design) tested at conditions matching/spanning expected non-dimensional parameter range for prototypical operating conditions. The experimental results were successfully compared to performance predicted by commercial CFD software (such as FLUENT) for test geometry/conditions. This helped to validate the CFD codes, which can be confidently used to optimize/modify design

The design assumes substantial progress in the development of W-alloy and ODS FS as structural materials. In addition, the fabrication of complex $\mathrm{W}$ components is challenging using conventional fabrication techniques (especially for such thin walled $\mathrm{W}$ tubes, of the order of $1 \mathrm{~mm}$ ). The fabrication techniques of such a $\mathrm{W}$ alloy cartridge including the end caps need to be demonstrated as well as techniques for joining the $\mathrm{W}$ alloy to the FS base through a functional gradient (in order to minimize thermal stresses). An effort has been started on this by Plasma Processes Inc. as part of an SBIR grant. W test articles have been fabricated as part of the first phase and will be tested in an electron beam test facility to provide an initial assessment of its performance.

\section{Material Considerations for Long Term Concepts}

Key material considerations for long term PFC concepts include structural material development for $\mathrm{W}$-alloy and ferritic steel as well as understanding the plasma material interface and its impact on the armor behavior and on the plasma performance.

\subsection{Structural Material Development}

\subsubsection{Ferritic Steel}


Over the last 15 years or so, a strong emphasis has been placed on the development of low activation ferritic/martensitic steel (with $8-12 \% \mathrm{Cr}$ ). The minimum operating temperature is governed by radiation hardening and ductile-to-brittle-temperature (DBTT) shift and is 200$250^{\circ} \mathrm{C}$, while the maximum operating temperature, based on thermal creep, is about $550^{\circ} \mathrm{C}$ [20]. Clearly, the latter is not sufficiently high to be joined to a W-alloy under its minimum operating temperature $\left(\sim 700^{\circ} \mathrm{C}\right)$. Thus, development of ODS ferritic steels with highertemperature capabilities is a key $R \& D$ need for this application. The minimum operating temperature of ODS-FS needs to be better assessed but is about $290^{\circ} \mathrm{C}$ (based on results for HT-9) [20]. The oxide dispersion significantly improves the (high-temperature) strength and thermal creep properties of ODS steels over conventional steels and increases the maximum operating temperature to $\sim 700^{\circ} \mathrm{C}$ or more.

Nano-structured ferritic alloys (NFA) are advanced ODS steels containing high concentrations of nano-size $\mathrm{Ti}-, \mathrm{Y}$ - and O-rich clusters, or nanoclusters, that provide significant (high-temperature) strength and creep resistance to these alloys (as illustrated in Figs. 14 and 15, respectively) [21,22]. The nanoclusters were initially discovered in the 12YWT NFA that was developed in Japan during the 1990's [23] and subsequently in MA957, which was developed and patented by INCO in 1978 [24]. However, these two NFA are not commercially available. Recent R\&D programs conducted in the US (ORNL and UCSB) have led to the development of 14YWT [25]. The 14YWT NFA produced at ORNL in numerous small $(<1.2 \mathrm{~kg})$ heats contains ultra-fine grain size and nanocluster dispersions that are responsible for the exceptional combination of high-temperature strength $\left(\sigma_{\mathrm{y}} \sim 300 \mathrm{MPa}\right.$ at $\left.800^{\circ} \mathrm{C}\right)$ and low temperature fracture toughness (transition temperature of $\left.150^{\circ} \mathrm{C}\right)[26,27]$. The nano-size features of NFA improve the radiation damage resistance by trapping point defects, including He, causing enhanced recombination and suppression of He bubble formation on grain boundaries that is responsible for embrittlement of structural materials in fusion reactors [28]. Therefore, nano-structured ferritic alloys offer the potential to extend the operating limit of ferritic steels from $\sim 550^{\circ} \mathrm{C}$ to $\sim 800^{\circ} \mathrm{C}$ for application in advanced nuclear energy systems.

INSERT FIGURE 14

INSERT FIGURE 15 
However, there are some key issues that need to be addressed in order to develop and validate these nano-structured ferritic alloys for fusion application. They include:

- $\quad$ Production in larger batch (e.g. the promising 14YWT NFA has currently only been produced in numerous small heats).

- $\quad$ Creep testing (currently in progress on 14YWT to study the effect of ultra-fine grain size).

- Very little fabrication experience with these high-strength materials other than hot rolling.

- Joining is a significant problem for ODS alloys.

- $\quad$ Problems due to mechanical alloying will limit scale-up efforts due mainly to high manufacturing costs.

- $\quad$ Effect of irradiation on mechanical properties and lifetime.

- $\quad$ Concern that important industrial companies, such as Special Metals and Plansee, have exited the ODS manufacturing business.

\subsubsection{W Alloy}

Present helium cooled DEMO divertor designs make use of the high temperature strength and good heat conductivity of refractory materials for use as structural material. For example, structural parts of $\mathrm{W}-1 \% \mathrm{La}_{2} \mathrm{O}_{3}$ (WL10), are used for operation at temperatures between about $600^{\circ} \mathrm{C}$ and $1300{ }^{\circ} \mathrm{C}$ in the EU HEMJ concept (see Section 3.1.1). The lower temperature is limited due to the transition to a steel part while the upper temperature limit is defined by the onset of recrystallization and/or loss of strength. The most critical issue of tungsten materials in connection with structural applications, however, is the rather high ductile-to-brittle transition temperature (DBTT). Consequently, a systematic screening study of impact bending properties of standard tungsten materials has been performed (in vacuum) to determine the influence of microstructure characteristics like grain size, anisotropy, and texture, or the influence of chemical composition $[29,30]$.

Desired criteria for structural divertor applications include creep strength ( 55 MPa for time to rupture of minimum 20,000 hours at $1200^{\circ} \mathrm{C}$ ), thermal conductivity ( 100 W/mK at $1200^{\circ} \mathrm{C}$ ), and DBTT $\left(\sim 300^{\circ} \mathrm{C}\right.$ in the unirradiated condition, measured by EU standard miniCharpy tests). An encouraging early observation, as illustrated in the available data plotted in 
Figures 16 and 17, is that the creep strength and thermal conductivity design goals are already satisfied by certain unirradiated WL10 materials [31].

\section{INSERT FIGURE 16}

\section{INSERT FIGURE 17}

Another issue, for which still no sufficient data are available, concerns the recrystallization behavior. The design is based on an operation time of about 20,000 hours. This would therefore be the minimum recrystallization time of a structural material. Results for pure tungsten showed material recrystallization at $1300{ }^{\circ} \mathrm{C}$. However, during other studies at the same temperature with WL10, recrystallization was not observed even after nearly 2000 hours.

As part of a collaboration between PLANSEE and FZK, five different tungsten rod materials (provided by PLANSEE) were studied: pure W, WL10 in two different conditions, potassium (0.005\%) doped tungsten (WVM), and WL10 with 1\% Re. Plates of pure W, WL10, and WVM were also used for the investigation. Finally, molybdenum-Ti-Zr (TZM) rod and plate material was used as reference.

The known benefits of lanthanum-oxide particles in tungsten are (1) an improvement on material processing, (2) the suppression of recrystallization, and (3) a slight creep strengthening. On the other hand, as confirmed by the study, the already insufficient fracture characteristic of pure tungsten is further deteriorated by the addition of lanthanum oxide (also but to a lesser degree by potassium). The study reveals furthermore that all considered tungsten rod materials fracture brittle below about $600{ }^{\circ} \mathrm{C}$. Earlier studies on commercial weld electrode materials revealed brittle transition temperatures of more than $900{ }^{\circ} \mathrm{C}$. Compared to that, the presently tested tungsten rod materials from PLANSEE confirm an improvement with respect to ductile fracture. Anyway, it could also be demonstrated that (rolled) plate materials in general perform worse than (rolled) rod materials. This can be certainly attributed to the different microstructures, which develop during material production. 
The following overall conclusions can be drawn from the various results with the investigated materials [29,30]:

- $\quad$ Molybdenum (TZM) rod samples exhibit a DBTT of $300{ }^{\circ} \mathrm{C}$, fracture fully ductile at $400^{\circ} \mathrm{C}$, and show no delamination.

- Un-notched pure tungsten rod specimens have a common DBTT of $450{ }^{\circ} \mathrm{C}$, fracture fully ductile at $450{ }^{\circ} \mathrm{C}$, and show no delamination.

- $\quad$ Tungsten rod specimens with sawed notches fracture fully ductile at $800{ }^{\circ} \mathrm{C}$ (transition temperature from delamination-to-ductile fracture of $750^{\circ} \mathrm{C}$ ).

- Tungsten rod specimens with electro discharge machined notches fracture fully ductile at $900{ }^{\circ} \mathrm{C}$ (transition temperature from delamination-to-ductile fracture of $850{ }^{\circ} \mathrm{C}$ ).

- WVM rod specimens are fully ductile at $1000{ }^{\circ} \mathrm{C}$ (delamination-to-ductile transition at $\left.950^{\circ} \mathrm{C}\right)$.

- WL10, WL10opt, W1Re1 $\mathrm{La}_{2} \mathrm{O}_{3}$ rod materials do not fracture (fully ductile up to $\left.1000^{\circ} \mathrm{C}\right)$.

- $\quad$ All tungsten rod materials show brittle fractures below $600{ }^{\circ} \mathrm{C}$.

- All plate materials (including TZM) exhibit severe delamination. The brittle-todelamination transition is $150{ }^{\circ} \mathrm{C}$ for TZM and $450{ }^{\circ} \mathrm{C}$ for pure tungsten plates.

The impact on further material development and fabrication may be summarized as follows:

- The microstructure has a significant influence on the transition to ductile fracture (rod micro-structure is more favorable than that of rolled plates).

- $\quad$ Oxide particles as well as potassium doping obviously promote delamination (probably by weakening the grain boundary cohesion). On the other hand, they also stabilize the grain boundaries and therefore suppress re-crystallization.

- $\quad$ Optimum fracture behavior can possibly reached only by avoiding machining and by aligning the grains along the contour of the according part. Therefore, for the fabrication of divertor thimbles a combination of deep drawing and twisting is recommended.

- $\quad$ For tungsten (with and without oxide particles) produced by sintering and rolling, forging, or swaging there seems to be a limit for DBTT (measured according to the standard described before) which is about at $400{ }^{\circ} \mathrm{C}$ or slightly above. 
A very important note is that this initial study focused on unirradiated material. The effect of irradiation on the material properties and in particular on embrittlement and operating temperature requirement is a major issue which should be part of the $\mathrm{R} \& \mathrm{D}$ in developing $\mathrm{W}$ alloy for power plant application.

\subsection{Plasma Material Interaction}

The major aspects of plasma material interaction are erosion, $\mathrm{T}$ retention, dust creation and plasma compatibility. The latter issues depend to a large extent on erosion, since for low-Z plasma facing components (PFCs) co-deposition of $\mathrm{T}$ will play a significant role and similarly the eroded material can act as a precursor for dust. Finally, the eroded material is the source for impurities in the plasma. Of course, there are also independent factors influencing the processes arising from other specific properties of the plasma facing material (PFM).

Most tokamaks are still operating with carbon-based PFCs and the largest operational experience exists for this plasma facing material (PFC). There are only two operating divertor tokamaks using the high-Z materials Mo and $\mathrm{W}$. Liquid metals - mainly Li - are under investigation in several midsized tokamaks, but their main application is still surface conditioning (see below) rather than the use as major PFC.

The major outcomes in the field of PMI in tokamaks can be summarized as follows:

- Carbon erosion is determined by both physical and chemical erosion, and tends to be high ( $\sim \%)$ over a wide range of incident energy, flux density and temperature experienced in present tokamaks. The exact details of dependence on flux, energy and temperature continue to be studied. [32,33]

- The erosion of high-Z materials is mainly caused by low-Z impurities; transients and accelerated particles (ICRF) play a significant role. [34,35] 
- 'Destructive' transients (large ELMs, disruptions) are usually not accessible in present day machines (except large ELMs in JET [36] and disruptions in Alcator C-Mod [37]); therefore laboratory experiments and modeling are indispensable.

- $\quad$ D-retention by co-deposition with $\mathrm{C}$ is quantitatively reproduced in dedicated tokamak experiments and appears as the dominant fuel retention mechanism. [38,39,40]

- D-retention in refractory metals is low from laboratory experiments and observations in AUG with W films [41,42,43], as illustrated in Fig. 18; however, the high D retention observed in C-Mod with bulk Mo [44] has yet to be understood.

- All candidate PFC materials can produce dust. However, dust investigations have just started, the sources are not well known and the extrapolation to ITER is difficult because of different classes of transients. $[45,46]$

- Conditioning by boronisation or Be evaporation is very efficient and helpful for primary $\mathrm{O}$ reduction; however, it is not available for long pulse operation [35,40,47,48]

- Liquid metals strongly change the edge plasma parameters and open up larger operational space; however, their application to a reactor is challenging due to temperature limitations from evaporation $[49,50]$.

- Other innovative concepts being studied include a low-Z material W surface consisting of boron or silicon loaded onto a $~ 50 \%$ void $\mathrm{W}$-surface. The resulting coating (1-2 $\mathrm{mm}$ thick) would protect the $\mathrm{W}$ from helium ion damage and enhance disruption tolerance via the effect of low-Z material vapor shielding. Critical issues include the need for real time boronization or siliconization to maintain the surface coating. Material samples of this low-Z material $\mathrm{W}$ surface are being fabricated and will be tested in DIII-D [51].

- $\quad$ Steady state operation (and neutron irradiation) may lead to a new class of challenges (see for example [40])

- Laboratory experiments and modeling are indispensable for the extrapolation of many aspects of PMI (see for example [43]).

\section{INSERT FIGURE 18}




\subsubsection{PMI Issues Beyond ITER}

ITER will provide valuable information about the loads to be expected in DEMO (steady and transient thermal loads as well as transient electromagnetic loads). However, ITER will provide limited ability to address the PMI research needs of a DEMO facility, in particular regarding the impact on PMI of high wall temperature and steady state, or high fluence, plasma exposure. In addition the issue associated with changing material properties due to large neutron fluence and its damage will likely not be addressed in ITER ( 0.5 dpa maximum) to the level that will be needed for a DEMO ( 20-40 dpa per operational year).

There is an important state of knowledge for ITER PMI issues associated with retention of the impinging fuel ions on the different materials in ITER. Most of the existing database ranges up to a fluence of a few $10^{25} \mathrm{~m}^{-2}$, with a few data points extending up to $1 \mathrm{x} 10^{26} \mathrm{~m}^{-2}$ and a single data point (for $\mathrm{W}$ retention) at a fluence of $1 \times 10^{27} \mathrm{~m}^{-2}$. In the case of some ITER materials, such as Be and pyrolytic graphite, retention appears to saturate before a fluence of $1 \times 10^{26} \mathrm{~m}^{-2}$, whereas in other ITER materials, such as tungsten and CFC, the retention is still increasing up to a fluence of $1 \times 10^{26} \mathrm{~m}^{-2}$. In DEMO, with its steady-state operation, much higher fluences will be achieved and the retention properties of tungsten surfaces at these extreme fluences will need to be understood, in particular the issue of longrange permeation, which will be important due to higher material temperature and larger surface ion fluence. Therefore one expects the behavior of fuel species within the material "bulk" to become more important in DEMO.

Even more disturbing from the DEMO PMI point of view, is the fact that almost the entire existing database has been collected at relatively low temperature (ambient temperature < $300^{\circ} \mathrm{C}$; transient operating temperatures with plasma $<500^{\circ} \mathrm{C}$ ). In DEMO, due to the need for efficient power conversion, the coolant temperature is typically expected to be around, or above, $600^{\circ} \mathrm{C}$. At these elevated temperatures, tritium permeation becomes an issue that must be understood and controlled. Tritium permeation in ITER is unlikely to be a serious concern because the divertor cassettes are scheduled for replacement fairly frequently (every few years, during low duty factor operation), and the majority of water-cooled surfaces are at $\sim 200^{\circ} \mathrm{C}$, a low temperature for bulk permeation. 
As an example of the effect of operating temperature, one can consider the recently-observed effects of mixed deuterium and helium bombardment of tungsten samples as the exposure temperature increases [52]. At low temperature $\left(200-300^{\circ} \mathrm{C}\right)$ tungsten samples exposed to pure deuterium bombardment ( 40-60 eV) tend to develop surface blisters that appear to be associated with an increase in the deuterium retention. As the exposure temperature increases the surface blisters tend to disappear and the retention level decreases. When helium is added (at a few percent level as expected from He ash) to the bombarding flux of tungsten at 200$300^{\circ} \mathrm{C}$, the presence of surface blisters is greatly reduced and the retention level is also low. However, when the surface temperature during the tungsten exposure is increased to about $800-1000^{\circ} \mathrm{C}$, the tungsten surface is observed to develop a nano-structured morphology. Although the deuterium retention is low due to the elevated exposure temperature, the development of tungsten nano-structures could lead to other problems. For example, the surface could overheat under high heat flux, owing to the expected poor thermal conductivity of the nano-structures, resulting in an increased sublimation rate, or the morphology could detach from the bulk and produce a source term for tungsten dust and effectively enhance erosion. In either case, this could have an impact on the lifetime of the tungsten armor.

An additional term that may impact the calculated lifetime of plasma-facing components operating at elevated temperature is the enhanced erosion that has been observed for many materials as the temperature of the sample is increased during energetic particle bombardment. The most well known example of this effect is the radiation-enhanced sublimation of carbon. However this effect has also been observed in solid metal samples (Be, W, Au) exposed at elevated temperature, as well as in liquid metal samples ( $\mathrm{Li}$ and Ga) [53].

It is clear that plasma-material interactions change as the temperature of the exposed surface changes. To date, the majority of the PMI database has been collected at relatively low temperature $\left(<500^{\circ} \mathrm{C}\right)$ whereas the need for DEMO is to perform similar measurements on prospective materials at much higher surface temperature and for extremely high fluence. These effects, coupled to the plasma exposed material behavior under neutron bombardment, 
are issues that need to be evaluated and understood to ensure the successful and reliable operation of a DEMO fusion power plant.

\section{Physics Considerations for Near Term and Long Term Concepts}

\subsection{SOL and Divertor Physics}

The design of ITER marked an important turning point in SOL/divertor physics. Pulse lengths of $\sim 10^{3}$ s necessitated water-cooled PFCs and the large step up in total power exhaust (> $150 \mathrm{MW}$ ) and size, combined with the (at that time) limit of $\sim 3-5 \mathrm{MW} / \mathrm{m}^{2}$ with active cooling, pointed to requirements to know the power deposition accurately before building ITER's divertor. This constraint is essentially absent in short pulse present devices where the dominant inertially-cooled carbon PFCs can easily withstand heat loads in excess of $10 \mathrm{MW} / \mathrm{m}^{2}$. Therefore, for the first time the plasma physics knowledge needed to be elevated to the point where imminent, non-negotiable engineering HHFC limits could be accommodated. Subsequent research oriented towards ITER carried out in the 1990's successfully demonstrated that operational regimes, such as partial detachment, appeared appropriate for successful power dissipation in the ITER divertor. Simultaneously developed plasma-fluid models were successful in recreating these results in extrapolation to ITER. Water-cooled PFCs meanwhile elevated heat loading capacity past $20 \mathrm{MW} / \mathrm{m}^{2}$.

While this progress provides confidence that ITER can meet power loading requirements, in fact it has become increasingly clear that many basic processes are not understood in the boundary plasma, and these unknowns lead to uncertainties for ITER, and certainly past ITER to DEMO, including:

- strong, convective and intermittent cross-field transport, leading to plasma filaments and associated flux interacting with the material structures outside the divertor;

- large scale, near sonic flows in the SOL that appear to control migration patterns for wall materials;

- an extremely cold and dense plasma formation in the private-flux region of the divertor that is apparently important for neutral pressure, and therefore He ash removal;

- uncertainty and inconsistency in the power widths at the divertor targets. 
Importantly, these observations also indicate that viewing the SOL issues in isolation (e.g. only heat exhaust) is too incomplete for prediction. For example the cold PF plasma and the filamentary transport could be associated with the achievement of detachment through enhanced ion-neutral collisions and cross-field transport respectively. Besides peak heat flux, predicting other important operational limits for ITER, such as tritium accumulation in PFC materials, rely on sorting out the complex aspect of particle and heat transport in the boundary. Achieving predictive capabilities as required for engineering design remains a daunting scientific challenge.

\subsection{Transients (ELM and disruption)}

Transient heating from MHD activity (ELMs and disruptions) becomes increasingly challenging and limiting for HHFC progression from ITER to DEMO. This arises from the simple consideration that fusion power density and therefore plasma kinetic pressure must increase, while for larger scale devices the ratio of surface area to volume decreases. Therefore it is inevitable that energy areal density is much larger and that rapid release (ms timescale) of this energy due to instability activity is more likely to send HHFC surfaces past their thermal limits (e.g. melting).

Disruptions are unexpected release of all the plasma energy. As already stated, uncontrolled release to small areas (e.g. divertor area) will assuredly lead to large scale surface melting or ablation. This leads to macroscopic (mm) material removal, a concern for HHFC lifetime. Perhaps even more important, the damaged surface may no longer be conforming to the local, grazing magnetic field, effectively producing leading edges that will rapidly re-melt under quiescent heat loading. This may effectively terminate the useful lifetime of the HHFC and force its replacement. Additionally, the loss of surface viability for the HHFC may lead to macroscopic material removal in otherwise quiescent operation, leading to another disruption due to radiative collapse (e.g. only a few $\mathrm{mm}^{3}$ of $\mathrm{W}$ are required to disrupt ITER). This raises the possibility that even a single disruption will force HHFC replacement. Research progress has been made towards mitigating material damage, such as radiation plasma termination with massive gas injection such as planned for ITER. Critical issues remain disruption avoidance and detection in order to optimize mitigation and provide HHFC protection. 
Edge Localized Modes (ELMs) may be an even more vexing issue than disruptions. While disruptions are unplanned (and therefore theoretically avoidable), ELMs are usually "part and parcel” of high confinement modes necessary for ITER (and reactor) core performance. ELMs are repetitive relaxations of the pedestal pressure gradient. As with disruptions, as tokamak energy density increases, the ELMs becomes more likely to cause surfaces to push past their thermal limits. Present estimates of the ELM size in ITER for regular H-mode indicates that the local heating may be $\sim 10$ times too high. Since one requires H-mode, a large recent research effort on eliminating or mitigating ELMs has started. As with disruptions, the constraint becomes greater in DEMO with its higher energy density. Recent success in eliminating ELMs with perturbed edge magnetic fields (RMP) are promising, but not sufficiently understood to support confident extrapolation [54]. Also, intentionally "pacing” the ELMs at a higher frequency using, for example, solid fuel pellet injection, thus decreasing the energy release per ELM is planned for ITER. Several physics issues remain outstanding. The exact response of the SOL/divertor to the ELM perturbation is unknown but critical, since in the end it is the peak heat/energy loading at HHFC that sets the ELM limit. The SOL/divertor response to RMP and pellet pacing is likewise largely unknown. For example, the RMP is accompanied by a strong reduction in pedestal density while the SOL density increases due the an increase in the particle transport across the separatrix [54], which may have a strong effect on recycling, erosion conditions and quiescent heat flux on the divertor.

As in the previous section it is noted that substantial advances in SOL/divertor physics understanding must be made to provide predictive capabilities for these complex, non-linear phenomena; yet predictions will be required for eventual DEMO designs.

\subsection{Physics Gaps}

Substantial physics knowledge gaps exist from present devices to ITER and then to DEMO. The five key PSI, and associated HHFC, issues of quiescent power exhaust, transient heating, neutron damage, erosion/film growth and tritium fuel control all take large steps, as illustrated in Table 2. These are linked to inevitable requirements for a fusion reactor: more fusion power and more fusion fuel burned with higher power and energy densities, sustained for year(s) at a time. It is also important to note that like any complex engineering system, it 
will become increasingly necessary to assess and assert control of the PSI issues. It is naïve to believe that single operating point equilibria will be established that work indefinitely. Indeed, it is obvious that the edge "system” will evolve on very long timescales as neutron and erosion damage accumulate. Thus, it seems critical that appropriate "sensor and actuators" are developed. However PSI and HHFC diagnosis become increasingly challenging in the nuclear fusion environment.

\section{INSERT TABLE 2}

Gaps/issues include:

- understanding of cross-field plasma heat and particle transport to predict heat widths at HHFC in the divertor and assure SOL designs that achieve $<10 \mathrm{MW} / \mathrm{m}^{2}$;

- integrated experience in confinement devices with hot PFC surfaces and high ambient temperature commensurate with those required in DEMO $\left(>600^{\circ} \mathrm{C}\right)$;

- long-range hydrogenic permeation, fuel storage and plasma wall fuelling at high temperatures in plasma confinement devices;

- understanding of multi-component PFC elements/materials interaction and effect on long-term HHFC viability;

- discovery of sources (and sinks) for dust production in plasma confinement devices with DEMO-relevant PFCs;

- determination of whether edge magnetic perturbations can be reliably used in a DEMO class device such that activation coil requirement, global pedestal/confinement requirement and quiescent heat load limits are simultaneously met; and

- demonstration of sufficient plasma/HHFC control to assure disruption free operation.

\section{Evaluation Methodology to Assess Current Readiness Level vis-à-vis the Long Term Objective}

Technology Readiness Levels (TRL) are a tool to help assess the readiness level of components or systems with respect to a product goal. TRLs express increasing levels of integration and environmental relevance, terms which must be defined for each application. TRLs are used by DOD, NASA, and other agencies. GAO has encouraged DOE and other 
government agencies to use TRLs to: provide a common language among the stakeholders; improve stakeholder communication regarding technology development; reveal the gap between a technology's current readiness level and the readiness level needed for successful inclusion in the intended product; identify at-risk technologies that need increased attention; and increase transparency of critical decisions.

The ARIES Team has recently developed TRLs to help assess readiness levels for top level fusion issues and systems [55]. The assignment of TRL levels requires an interpretation of the precise meaning of the language in the definition of TRLs, as well as a judgment on the relevance of existing facilities and $R \& D$ programs throughout the world. As a result, there is an element of uncertainty in the assignment of TRLs. The evaluation performed by the ARIES Team was based on the relatively broad expertise of the team. However, it is clear that the work represents only a starting point, and that additional effort will be required to evolve this methodology and to evaluate readiness through broader community participation.

One of the issues assessed was "Heat and Particle Flux Handling." Table 3 summarizes the TRL definitions for that case, which relates directly to PFCs. A key PFC challenge is the surface heat flux removal. Constraints on efficient power conversion further exacerbate this problem, due to the requirement of high-temperature operation. In addition, plasma-material interactions can lead to armor erosion and tritium retention, impacting the PFC and plant safety. The definitions of the TRL levels shown in Table 3 are intended to be as technically detailed as possible to allow for an accurate assessment and to minimize any subjectivity, but yet applicable to all subsystems in this issue category (including first wall, baffle, limiter, and divertor PFCs as well as heating and current drive PFCs).

When applying similar TRLs to the goal of ITER (i.e. a TRL of 9 represents successful operation of the divertor system in ITER), the current ITER divertor design is very high in readiness level with a TRL of 7-8. However, when applying these TRLs to the goal of a DEMO or power plant divertor (i.e. a TRL of 9 represents successful operation of the divertor system in DEMO), the current He-cooled $+\mathrm{W}$-alloy divertor designs are still at a very early development phase, perhaps a TRL of 2-3. This clearly illustrates the gap in technology between near-term and long-term divertor concepts. 
INSERT TABLE 3

\section{Key Observations and Discussion}

Based on the material presented in the previous sections, it is clear that there are major differences between near-term and long-term divertor concepts. These can be highlighted through the following five categories: (1) divertor materials and conditions; (2) level of R\&D effort; (3) steady state and transient loads; (4) plasma/material interaction conditions; and (5) technology readiness level. The contrasts between near-term and long-term concepts under these categories are summarized in Table 4 and discussed below.

\section{INSERT TABLE 4}

The ITER divertor utilizes CuCrZr as structural material for the coolant tube, austenitic steel as structural material for the cassette body, and W and CFC as armor material. It is cooled with water at $100^{\circ} \mathrm{C}$ and is designed for neutron irradiation corresponding to a fraction of a dpa. Currently considered DEMO or power plant concepts are very different, utilizing W alloy as structural material joined to an ODS ferritic steel manifold and cooled by $\mathrm{He}$ at $\sim 600^{\circ} \mathrm{C}$ at irradiation levels of several tens of dpa. This means that not much will be learned from the ITER divertor design, development and qualification, and operation which could be applicable to a DEMO or power plant concept

The ITER divertor design is mature and has been developed through an extensive R\&D and qualification program over the last 15 years or so, including progressively more integrated experiments and progressively larger mock-ups. This has brought the ITER divertor design to the eve of procurement. In contrast, the proposed DEMO or power plant divertor designs look promising but are not mature yet; the supporting R\&D is in its early stages, with small mockup testing having started but with much required in terms of material development, fabrication and qualification (especially for W alloy but also for ODS ferritic steel). Looking at the time and effort required to develop the ITER divertor using already well established materials (austenitic steel, CuCrZr) for low temperature and modest irradiation level ( $<1 \mathrm{dpa})$ is revealing. If we want to be serious about developing a power plant divertor design, we need to start now in particular if we intend to test this divertor in a long-pulse, high-power 
plasma confinement device prior to DEMO; we need also to find out sooner than later whether such W-alloys (or other refractory alloys) would work under the operating temperature and irradiation conditions of a power plant (and could be fabricated) so as to have the time to find other solutions if they do not.

The ITER PFCs are designed for very demanding loading conditions to provide some margin for the operation of an experimental machine. They are cooled by low temperature water, which increases the margin for phase change or maximum allowable material temperature to be reached. For example, the ITER divertor vertical targets are designed for up to $20 \mathrm{MW} / \mathrm{m}^{2}$ quasi-steady-state heat load. In addition, the ITER PFCs have to accommodate a range of off-normal conditions, including disruptions, ELMs and VDEs as described in Section 2.1. Power plant or DEMO divertor concepts have to operate at higher temperature $\left(\sim 600^{\circ} \mathrm{C}\right.$ or higher) to convert the energy deposition in the divertor region to efficient power production. Thus, margins are reduced and these divertor concepts are limited to a maximum heat flux of $\sim 10 \mathrm{MW} / \mathrm{m}^{2}$. In addition, the power plant/DEMO PFCs can accommodate only a few disruptions and/or uncontrolled ELMs per year and no VDEs. Thus, avoidance and/or mitigation of such off-normal events are a major requirement for power plant application and should be an R\&D priority. For example, recent studies at DIII-D are encouraging, showing that Resonant Magnetic Pertubations (RMP) can be effective for ELM suppression over a wide variety of plasma shapes and operating conditions. These results could be scaled to ITER but a number of physics questions still need to be addressed in order to reliably do so [54].

The plasma material interface conditions in ITER are very different from those considered for a power plant. ITER utilizes 3 plasma interface materials: Be, CFC and $\mathrm{W}$ operating at low temperature $\left(\sim 200^{\circ} \mathrm{C}\right)$. Concepts for DEMO and power plant generally consider a W divertor and either a $\mathrm{W}$ coated first wall or, if allowable, a bare ferritic-steel first wall operating at high temperature $\left(\sim 700^{\circ} \mathrm{C}\right)$. Temperature dictates so many processes that it is very important to have fusion testing under these conditions prior to DEMO.

When applying the Technology Readiness Levels (TRLs) as a tool to assess the readiness of the PFCs, the ITER PFCs are toward the end of the TRL scale ( 7-8) for the goal of operation in ITER. However, when applying TRLs to the DEMO/power plant PFCs with the goal of operation in DEMO, the PFCs are at very early stages of readiness (TRLs 2-3). 
This is again a sobering observation, illustrating so clearly the work ahead of us if we want to be serious about developing PFCs for DEMO and power plants.

\section{Summary and Conclusions}

This paper has summarized information primarily from very informative presentations and discussions at the "International HHFC Workshop on Readiness to Proceed from Near Term Fusion Systems to Power Plants”[3], and focused on tokamak divertors with solid surfaces. The conclusions offered below are based on the discussions in this workshop and further discussion among the authors and the working assumption that a DEMO will be a high performance D-T tokamak. Thus, we are assuming that heat from the divertor is removed at relatively high temperature and coupled with heat from the blanket to drive a high-efficiency power cycle (e.g. a He-cooled power core linked through a heat exchanger to Brayton power cycle).

The requirements for power generation for a DEMO lead immediately to several major differences between ITER and DEMO (and a power plant). Two of these important differences are (1) the operating temperature of the material and (2) the neutron fluence for the lifetime of the divertor (and other PFCs). The consideration of operating temperature alone for DEMO rules out the copper alloys and stainless steel in the ITER. Also the projections for mechanical and thermal properties for the ITER divertor can be made with confidence for the most part based on past and ongoing fission irradiation experiments, although there are still concerns about some aspects of damage and trapping of tritium. Although there are general lessons from ITER and its divertor regarding such elements as design integration and remote handling, we do not expect to learn much from the R\&D, fabrication and operation of PFCs in ITER that will be applicable to DEMO or a fusion power plant.

In this paper, we highlighted development needs for a DEMO divertor and used the concept of technology readiness levels as a programmatic tool for measurement of progress and readiness. We conclude that developing PFCs for DEMO and beyond will require a focused R\&D campaign on high heat flux components for DEMO. This effort will require a much 
higher level of effort than is currently being expended and must include the following elements.

- Development of armor and structural materials (e.g., $\mathrm{W}$ or other refractory alloys for divertor PFC and ODS FS for the manifold at the back) to qualify them for DEMO conditions including operating temperature and irradiation levels.

- Validated operating techniques and technologies that provide sufficient mitigation and/or avoidance of transient loads to satisfy requirements for design and licensing of a DEMO, e.g., no VDEs and only a few disruptions and ELMs would be allowable for a DEMO or power plant.

- Program of modeling well-coordinated with gradually more integrated experiments to develop a divertor concept for DEMO and beyond.

- Operation of PFCs with a high temperature wall leading to testing in a fusion device before DEMO.

We conclude that to progress up the scale of Technology Readiness Levels to the point where the risk to build a DEMO could be judged as acceptable will require a strong and committed program for development of PFCs that will combine predictive modeling of materials and the effects at the edge of the plasma, development of materials, and fabrication and high heat flux testing on progressively larger scale mock-ups leading to prototypic operation in a fusion device.

\section{Acknowledgement}

This paper resulted in major part from very informative presentations and discussions at the "International HHFC Workshop on Readiness to Proceed from Near Term Fusion Systems to Power Plants”, which was held at the University of California, San Diego on December 1012, 2008, as part of the series of periodical ARIES Workshops and Town Meetings [1]. The workshop was quite successful in achieving its main objective of bringing together participants from the design, physics and material communities to: better characterize the 
international status of current HHFC design concepts for power plants; compare it to the present stage of development and experimental information for near term concepts (ITERlike); and better understand how to evaluate the current status with respect to the end goal (power plant HHFC concepts) and what needs to be done to get there. The authors gladly acknowledge the contribution of all meeting participants. 


\section{References}

[1] D. Maisonnier, I. Cook, P. Sardain, L. Boccaccini, L. Di Pace, L. Giancarli, P. Norajitra, A. Pizzuto and the PPCS Team, DEMO and fusion power plant conceptual studies in Europe," Fusion Engineering \& Design, 81 (2006) 1123-1130.

[2] A plan for the development of fusion energy, Report of the Fusion Energy Sciences Advisory Committee Fusion Development Path Panel, US Department of Energy, Office of Science, DOE/SC-0074, March 2003.

[3] International HHFC Workshop on Readiness to Proceed from Near Term Fusion Systems to Power Plants, University of California, San Diego, CA, USA, December 10-12, 2008, http://aries.ucsd.edu/IHHFC/index.html

[4] A. Loarte et al., Power and particle fluxes at the plasma edge of ITER: Specifications and physics basis, paper IT/P6-13, $22^{\text {nd }}$ IAEA Fusion Energy Conference, Geneva, Switzerland (13-18 October 2008).

[5] M. Merola, ITER PFC (Divertor, First Wall) design, presented at the International HHFC Workshop on Readiness to Proceed from Near Term Fusion Systems to Power Plants, University of California, San Diego, CA, USA, December 10-12, 2008, available at http://aries.ucsd.edu/IHHFC/index.html; see also Project Integration Document, ITER Organization (IDM 2234RH), Cadarache, France, January 2007.

[6] P. Lorenzetto, EU considerations on design and qualification of PFC's for near term machines (ITER), presented at the International HHFC Workshop on Readiness to Proceed from Near Term Fusion Systems to Power Plants, University of California, San Diego, CA, USA, December 10-12, 2008, available at http://aries.ucsd.edu/IHHFC/index.html.

[7] M. Merola, M. Akiba, V. Barabash, I. Mazul, Overview on fabrication and joining of plasma facing and high heat flux materials for ITER, J. Nucl. Mater, 307-311 (2002) 1524-1532.

[8] M. Roedig, W. Kuehnlein, J. Linke, D. Pitzer, M. Merola, E. Rigal, B. Schedler, E. Visca: Post irradiation testing of samples from the irradiation experiments PARIDE 3 and PARIDE 4, J. Nucl. Mater. 329 - 333 (2004) 766-770.

[9] I. Bobin-Vastra, F. Escourbiac, M. Merola, P. Lorenzetto, Activity of the European high heat flux test facility: FE200, Fus. Eng. and Des. 75-79 (2005) 357-363. 
[10] G. Pintsuk, J. Compan, T. Hirai, J. Linke, M. Rödig, Effect of neutron irradiation on the thermal shock behaviour of tungsten and carbon based materials, EUROMAT 2007, Nürnberg, Sept. 10-13, 2007.

[11] J. Schlosser, F. Escourbiac, F. Cismondi, M. Missirlian, J. Boscary, M. Merola, Thermal hydraulic design of the high heat flux components in the controlled fusion machines TORE SUPRA and ITER, Proceedings of International Topical Meeting on Nuclear Reactor Thermal Hydraulics - Pittsburgh, Pennsylvania, September 30October 4, 2007 .

[12] A. R. Raffray, L. El-Guebaly, T. Ihli, S. Malang, X. Wang, and the ARIES-CS Team, Engineering design and analysis of the ARIES-CS power plant," Fusion Science \& Technology, 54 (3) (October 2008) 725-746.

[13] A. R. Raffray, and G. Federici, RACLETTE: A model for evaluating the thermal response of plasma facing components to slow high power plasma transients. Part I: Theory and description of model capabilities, Journal of Nuclear Materials, 244 (1997) 85-100.

[14] S. Hermsmeyer and S. Malang, Gas-cooled high performance divertor for a power plant, Fusion Engineering and Design, 61-62 (2002) 197-202.

[15] X. Wang, S. Malang, A. R. Raffray and the ARIES Team, Design optimization of high-performance helium-cooled divertor plate concept, presented at the $18^{\text {th }}$ ANS TOFE, September 2008, to appear in proceedings.

[16] T. Ihli, A. R. Raffray, S. Abdel-Khalik, M. Shin and the ARIES Team, Design and performance study of the helium-cooled T-tube divertor concept, Fusion Engineering \& Design, 82 (2007) 249-264.

[17] T. Ihli, R. Kruessmann, I. Ovchinnikov, P. Norajitra, V. Kuznetsov and R. Giniyatulin, An advanced He-cooled divertor concept: Design, cooling technology, and thermohydraulic analyses with CFD, Fusion Engineering and Design, 75-79 (November 2005) 371-375.

[18] P. Norajitra, S. Abdel-Khalik, L. M. Giancarli, T. Ihli, G. Janeschitz, S. Malang, I. V. Mazul and P. Sardain, Divertor conceptual designs for a fusion power plant, Fusion Engineering \& Design, in press.

[19] L. Crosatti, D. L. Sadowski, S. I. Abdel-Khalik, M. Yoda, and the ARIES Team, Thermal performance of a prototypical gas-cooled T-tube divertor module with single-sided heating, presented at the $18^{\text {th }}$ ANS TOFE, September 2008, to appear in proceedings. 
[20] S.J. Zinkle and N.M. Ghoniem, Operating temperature windows for fusion reactor structural materials , Fusion Engineering and Design, 51-52 (2000) 55-71.

[21] R.L. Klueh et al., A comparison of some commercial and experimental alloys, J. Nucl. Mater., 341 (2005) 103-114.

[22] D. T. Hoelzer, private communication (from unpublished results, International Nuclear Energy Research Initiative (INERI) Project, 2007-001-F (2008)).

[23] I.-S. Kim et al., Effect of Ti and W on the mechanical properties and microstructure of $12 \%$ Cr base mechanical-alloyed nano-sized ODS ferritic alloys, ISIJ Int. 43, (2007) 1640-1646.

[24] J. J. Fisher, US Patent 4,075,010, 1978.

[25] M. J. Alinger et al., The development and stability of $\mathrm{Y}-\mathrm{Ti}-\mathrm{O}$ nanoclusters in mechanically alloyed Fe-Cr based ferritic alloys, J. Nucl. Mater., 329-333 (2004) 382-386.

[26] D. T. Hoelzer et al., Influence of particle dispersions on the high-temperature strength of ferritic alloys, J. Nucl. Mater., 367-370 (2007) 166-172.

[27] D. A. McClintock et al., Mechanical properties of neutron irradiated nanostructured ferritic alloy 14YWTJ. Nucl. Mater., 386-388 (2009) 307-311.

[28] T. Yamamoto et al., The transport and fate of helium in nanostructured ferritic alloys at fusion relevant He/dpa ratios and dpa rates, J. Nucl. Mater., 367-370 (2007) 399410.

[29] M. Rieth, A. Hoffmann, Fracture behaviour of tungsten-based alloys depending on microstructure and notch fabrication method, to appear in Proc. of $18^{\text {th }}$ Topical Meeting on the Technology of Fusion Energy (TOFE), Sept. 28-Oct. 2, 2008, San Francisco, CA, USA.

[30] M. Rieth, A. Hoffmann, Impact bending tests on selected refractory materials, Advanced Materials Research, 59 (2009) 101-104.

[31] M. Rieth, A. Hoffmann, B. Dafferner, S. Heger, U. Jäntsch, M. Klimenkov, P. Lukits, M. Rohde, H. Zimmermann, Tungsten as structural DEMO divertor material, Proc. of Annual Meeting on Nuclear Technology, May 12-14, 2009, Dresden, Germany.

[32] J. Roth et al., Flux dependence of carbon chemical erosion by deuterium ions, Nucl. Fusion 44 (2004) L21.

[33] J. Brezinsek et al., Report of the SEWG on Materials Migration, Annual Meeting of the European Taskforce of Plasma Wall Interaction, Oct. 27-29, 2008, Frascati 
[34] R. Dux et al., Plasma-wall interaction and plasma behaviour in the non-boronised all tungsten ASDEX Upgrade, J. Nucl. Mater, in press.

[35] B. Lipschultz et al., Influence of boronization on operation with high-Z plasma facing components in Alcator C-Mod, J. Nucl. Mater. 363-365 (2007) 1110-118.

[36] A. Kreter et al., Nonlinear impact of edge localized modes on carbon erosion in the divertor of the JET tokamak Phys. Rev. Lett. 102, 045007 (2009).

[37] D. Whyte, et al, Disruption mitigation on Alcator C-Mod using high-pressure gas injection: Experiments and modeling toward ITER, Journal of Nuclear Materials, 363-365 (June 2007) 1160-1167.

[38] J. Likonen et al., "Post-mortem measurements of fuel retention at JET with MKII-SRP divertor," J. Nucl. Mater, in press.

[39] T. Loarer, Fuel retention in tokamaks, J. Nucl. Mater, in press.

[40] B. Pegourie et al., Overview of the deuterium inventory campaign in Tore Supra: Operational conditions and particle balance, J. Nucl. Mater, in press.

[41] M. Mayer et al., Carbon balance and deuterium inventory from a carbon dominated to a full tungsten ASDEX Upgrade, J. Nucl. Mater, in press.

[42] V. Rohde et al., Dynamic and static deuterium inventory in ASDEX Upgrade with tungsten first wall, $22^{\text {nd }}$ IAEA Fusion Energy Conference 2008, Geneva, EX/P4-3 (subm. to Nucl. Fusion).

[43] J. Roth et al., Recent analysis of key plasma wall interactions issues for ITER, J. Nucl. Mater., in press.

[44] B. Lipschultz et al., Operation of Alcator C-Mod with high-Z plasma facing components and implications, Phys. Plasmas 13, 056117 (2006).

[45] S.-H. Hong et al., Investigation of temporal evolution and spatial distribution of dust creation events in DITS campaign using visible CCD cameras in Tore Supra, J. Nucl. Mater., in press.

[46] D. L. Rudakov et al., Migration of artificially introduced micron-size carbon dust in the DIII-D divertor, J. of Nucl. Mater. 363-365 (2007) 227-232.

[47] W. P. West et al., Plasma impurity content, gas fueling, and exhaust on DIII-D over extended periods between boronizations, J. Nucl. Mater., in press. 
[48] A. Kallenbach et al., Non-boronized compared with boronized operation of ASDEX Upgrade with full-tungsten plasma facing components, Nucl. Fusion, 49 No 4 (April 2009) 045007 (10pp).

[49] G. Mazzitelli et al., Status and perspective of the liquid material experiments in FTU and ISTTOK, $22^{\text {nd }}$ IAEA Fusion Energy Conference 2008, Geneva, EX/P4-6.

[50] H.W. Kugel et al., NSTX experiments with lithium plasma-facing components -Recent results and future plans, 50th Meet. Am. Phys. Soc., Div. of Plasma Physics 2008, Dallas, NP6.84.

[51] C.P.C. Wong, Innovative Tokamak DEMO first wall and divertor material concepts, to be published in J. of Nucl. Mat. (2009).

[52] M. Baldwin et al., The effects of high fluence mixed-species (deuterium, helium, beryllium) plasma interactions with tungsten, J. Nucl. Mater., in press (2009).

[53] R.P. Doerner et al., High temperature erosion of beryllium, J. Nucl. Mater. 337-339 (2005) 877-881.

[54] T. E. Evans, M. E. Fenstermacher, R. A. Moyer, T. H. Osborne, et al., RMP ELM suppression in DIII-D plasmas with ITER similar shapes and collisionalities, Nucl. Fusion 48 (2008) 024002; see also T. Evans, Controlling SOL and pedestal MHD, presented at the International HHFC Workshop on Readiness to Proceed from Near Term Fusion Systems to Power Plants, University of California, San Diego, CA, USA, December 10-12, 2008, available at http://aries.ucsd.edu/IHHFC/index.html.

[55] M. S. Tillack, D. Steiner, L. M. Waganer, S. Malang, et al., Issues and R\&D needs for commercial fusion energy: An interim report of the ARIES technical working groups, UCSD Technical Report, UCSD-CER-08-01, July 2008. 


\section{List of Tables}

Table 1 CHF margin for ITER Vertical Target

Table 2 Comparison of Plasma Parameters from Present-day Tokamaks to ITER to DEMO

Table 3 Technology Readiness Levels for PFCs

Table 4 Key Differences Between Near-Term Divertor Concept (ITER) and DEMO/Power Plant Concepts 
Table 1 CHF margin for ITER Vertical Target

\begin{tabular}{|c|c|c|c|}
\hline $\begin{array}{c}\text { CFC } \\
\text { thickness }\end{array}$ & IHF & Defect & $\begin{array}{c}\text { CHF } \\
\text { Margin }\end{array}$ \\
\hline \multirow{3}{*}{$18 \mathrm{~mm}$} & $10 \mathrm{MW} / \mathrm{m}^{2}, \mathrm{ss}$ & $\begin{array}{c}\text { No } \\
\text { yes }\end{array}$ & $\begin{array}{c}3,5 \\
3,8\end{array}$ \\
\cline { 2 - 4 } & $20 \mathrm{MW} / \mathrm{m}^{2}, 10$ & No & 2,2 \\
\cline { 2 - 4 } & $\mathrm{sec}$ & yes & 2,0 \\
\hline \multirow{3}{*}{$7 \mathrm{~mm}$} & $10 \mathrm{MW} / \mathrm{m}^{2}, \mathrm{ss}$ & No & 3,5 \\
& & yes & 3,3 \\
\cline { 2 - 4 } & $20 \mathrm{MW} / \mathrm{m}^{2}, 10$ & No & 1,6 \\
\cline { 3 - 4 } & $\mathrm{sec}$ & yes & 1,4 \\
\hline
\end{tabular}


Table 2 Comparison of Plasma Parameters from Present-day Tokamaks to ITER to DEMO

\begin{tabular}{|c|c|c|c|c|}
\hline Issue / Parameter & $\begin{array}{c}\text { Present } \\
\text { Tokamaks }\end{array}$ & ITER & DEMO & Consequences \\
\hline $\begin{array}{l}\text { Energy exhaust (production) } \\
\text { GJ/ day }\end{array}$ & $\sim 10$ & 3,000 & 60,000 & $\begin{array}{l}\text { - active cooling } \\
\text { - max. tile thickness } \sim 10 \mathrm{~mm}\end{array}$ \\
\hline $\begin{array}{l}\text { Transient energy exhaust from } \\
\text { plasma instabilities } \\
\Delta T \sim M J / A_{\text {wall }}\left(m^{2}\right) /(1 \mathrm{~ms})^{1 / 2}\end{array}$ & $\sim 2$ & 15 & 60 & $\begin{array}{l}\text { - require high } \mathrm{T}_{\text {melt/ablate }} \\
\text { - limit? } \sim 40 \text { for } \mathrm{C} \text { and } \mathrm{W} \\
\text { - surface distortion }\end{array}$ \\
\hline $\begin{array}{l}\text { Yearly neutron damage in } \\
\text { plasma-facing materials } \\
\text { displacements per atom }\end{array}$ & $\sim 0$ & $\sim 0.5$ & 20 & $\begin{array}{l}\text { - evolving material properties: } \\
\text { thermal conductivity, swelling, } \\
\text { traps for tritium }\end{array}$ \\
\hline $\begin{array}{l}\text { Max. gross material removal } \\
\text { rate with } 1 \% \text { erosion yield } \\
\text { ( } m m \text { / operational-year) }\end{array}$ & $<1$ & 300 & 3000 & $\begin{array}{l}\text { - must redeposit locally } \\
\text { - limits lifetime } \\
\text { - produces films }\end{array}$ \\
\hline $\begin{array}{l}\text { Tritium consumption } \\
\text { ( } / \text { / day) }\end{array}$ & $<0.02$ & 20 & 1000 & $\begin{array}{l}\text { - Tritium retention in materials } \\
\text { and recovery }\end{array}$ \\
\hline
\end{tabular}


Table 3 Technology Readiness Levels for PFCs

\section{Issue-Specific Description}

1 System studies to define parameters, tradeoffs and requirements on heat \& particle flux level, effects on PFC's.

PFC concepts including armor and cooling configuration explored. Critical parameters characterized. PMI and edge plasma modeling.

Data from coupon-scale heat and particle flux experiments; modeling of governing heat and mass transfer processes as demonstration of function of PFC concept.

Bench-scale validation through submodule testing in lab environment

4 simulating heat or particle fluxes at prototypical levels over long times; coupons under representative neutron irradiation level/duration.

Integrated module testing of PFC concept in an environment simulating

the integration of prototypical-level heat and particle fluxes over long

5 times. Coupon irradiation testing of $\mathrm{PFC}$ armor and structural material to end-of-life fluence.

Integrated testing of the PFC concept subsystem in an environment simulating the integration of heat \& particle fluxes at prototypical levels over long times (preferably with some level of neutron irradiation).

7 Prototypic PFC system demonstration in a fusion device.

8 Actual PFC system demonstration and qualification in a fusion energy device over long operating times.

9 Actual PFC system operation to end-of-life in a fusion reactor with prototypical conditions and all interfacing subsystems.

\section{Program Elements}

Design studies, basic research

Code development, applied research

Small-scale facilities:

e.g., e-beam and plasma simulators

Larger-scale facilities for submodule testing, high-temperature + all expected conditions. Neutron irradiation (fission).

Integrated facility with prototypical plasma particle + heat flux; material irradiation test facility such as IFMIF

Integrated large test facility with prototypical plasma particle \& heat flux (preferably with some neutron irradiation effect) (e.g. DD confinement device).

Fusion device, e.g. ITER (with prototypical divertor system), CTF

CTF

DEMO (1t $1^{\text {st }}$ a kind power plant) 
Table 4 Key Differences Between Near-Term Divertor Concept (ITER) and DEMO/Power Plant Concepts

\begin{tabular}{|c|c|c|}
\hline & Near Term Concept (ITER) & $\begin{array}{l}\text { Long Term Concept } \\
\text { (DEMO/Power Plant) }\end{array}$ \\
\hline $\begin{array}{l}\text { Divertor materials } \\
\text { and conditions }\end{array}$ & $\begin{array}{l}\text { ITER: } \\
100^{\circ} \mathrm{C} \text { subcooled water, } \\
\text { CuCrZr tube } \\
\text { austenitic SS } \\
\text { W/CFC armor }\end{array}$ & $\begin{array}{l}\text { Power plant (Demo): } \\
600-700^{\circ} \mathrm{C} \text { He, } \\
\text { W-alloy, ODS FS } \\
\text { W armor }\end{array}$ \\
\hline Level of R\&D effort & $\begin{array}{l}\text { Extensive R\&D for ITER } \\
\text { divertor }(15 \text { years }+) \text { : at the } \\
\text { edge of procurement }\end{array}$ & $\begin{array}{l}\text { R\&D in early stages for power } \\
\text { plant divertor material and } \\
\text { configuration (must be } \\
\text { realistic about time and effort } \\
\text { required) }\end{array}$ \\
\hline $\begin{array}{l}\text { Steady state and } \\
\text { transient loads }\end{array}$ & $\begin{array}{l}\text { ITER divertor designed for } \\
\text { demanding steady-state and } \\
\text { off-normal conditions }\end{array}$ & $\begin{array}{l}\text { Power plant q’’ on divertor } \\
\text { limited to } ~ 10 \mathrm{MW} / \mathrm{m}^{2} \text {; } \\
\text { no VDEs; } \\
\text { very few } \\
\text { disruptions per year }\end{array}$ \\
\hline $\begin{array}{l}\text { Plasma/Material } \\
\text { Interaction } \\
\text { Conditions }\end{array}$ & $\begin{array}{l}\text { ITER PMI: } \\
3 \text { materials }(\mathrm{Be}, \mathrm{C}, \mathrm{W}) ; \\
\text { low wall temperature }\left(\sim 200^{\circ} \mathrm{C}\right)\end{array}$ & $\begin{array}{l}\text { Power plant PMI: } \\
\text { W (bare wall?); } \\
\text { high wall temperature }\left(\sim 700^{\circ} \mathrm{C}\right) \\
\text { (need testing } \\
\text { under these conditions) }\end{array}$ \\
\hline $\begin{array}{l}\text { Technology } \\
\text { Readiness Level }\end{array}$ & $\begin{array}{l}\text { ITER PFC toward the end of } \\
\text { TRL scale }\end{array}$ & $\begin{array}{l}\text { Power plant PFC at early TRLs } \\
\text { (providing a guide as to what is } \\
\text { needed next) }\end{array}$ \\
\hline
\end{tabular}




\section{Figure Captions}

Figure 1 ITER plasma-facing materials for initial operation phase with hydrogen

Figure 2 Schematic of an ITER divertor cassette

Figure 3 Details of the ITER divertor vertical target

Figure 4 Full-scale ITER divertor mock-up

Figure 5 Medium-scale CFC and W monoblock mock-up

Figure 6 Damage mechanisms during thermal shock loads on tungsten and CFC [10]

Figure $7 \quad$ Validation of heat transfer modelling from CHF testing

Figure 8 Maximum phase change thickness of a W first wall as a function of transient energy deposition for deposition times of 1 and 3 ms (DCLL case)

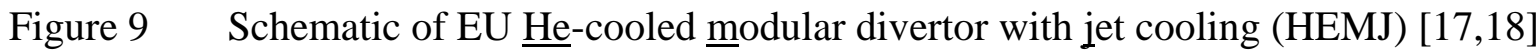

Figure 10 Combined helium loop \& electron beam facility (60 kW, $27 \mathrm{keV}$ ) at Efremov Institute for divertor testing.

Figure 11 HEMJ mock-ups and mock-up holder.

Figure 12 Schematic of ARIES T-tube divertor $[12,16]$

Figure 13 Temperature and combined stress distributions for ARIES T-tube under $10 \mathrm{MW} / \mathrm{m}^{2}$ heat flux.

Figure 14 Comparison of the high-temperature strength of 3 nanostructured ferritic alloys (12YWT, MA957 and Plansee ODS alloy) and of a tempered martensitic 9Cr steel [21]

Figure 15 Creep properties of two nanostructured ferritic alloys (12YWT and MA957) compared to tempered martensitic 9Cr steel [22]

Figure 16 Creep strength of tungsten in form of a Larson-Miller plot for times to rupture (desirable design value is shown) [31]

Figure 17 Thermal conductivity of $\mathrm{W}$ measured by laser flash analysis (desirable design value is shown) [31]

Figure 18 Deuterium retention in $\mathrm{W}$ as a function of fluence from laboratory and ASDEX Upgrade experiments [41] 